\title{
DETECCIÓN POR PCR DE ANAPLASMA SPP. EN CAPRINOS DEL MUNICIPIO DE LOS SANTOS, SANTANDER-COLOMBIA
}

\author{
Ángela Jiménez ${ }^{\star}$, M.Sc. $_{1}$, Alba García, Est. ${ }_{1}$, Carolina Angulo, Est. ${ }_{1}$, Joaquín Gómez, Esp. ${ }_{1}$
}

${ }_{1}$ Laboratorio de Biología Molecular, Universidad Cooperativa de Colombia, sede Bucaramanga, Colombia

Recibido: 11 de junio del 2013 Aprobado: 20 de noviembre del 2013

* Autor de correspondencia: Ángela Jiménez, Facultad de Medicina Veterinaria y Zootecnia, Universidad Cooperativa de Colombia, Bucaramanga, Colombia, A.A. 2019. Teléfono: 6458500. Correo electrónico: angela.jimenez@campusucc.edu.co

Cómo citar este artículo: Jiménez A, García A, Angulo C, Gómez J. Detección por PCR de Anaplasma spp. en caprinos del municipio de Los Santos, Santander Colombia. Spei Domus. 2013; 9(19): 11-6.

Resumen. Mediante PCR semianidada se amplificó una porción de 347 pb del gen msp5 para determinar la presencia de Anaplasma spp. en caprinos de la Mesa de Los Santos, Santander. A partir de 600 individuos se seleccionó una muestra de 99 animales utilizando una afijación proporcional. A cada uno de los caprinos se les realizó un examen semiológico y la extracción de una muestra sanguínea para PCR semi-anidada, medición de hematocrito, hemoglobina, evaluación de la morfología de los glóbulos rojos y observación directa del microorganismo en extendidos de sangre periférica teñidos con Giemsa. El 7,1\% de los caprinos resultaron positivos por PCR y $4 \%$ por observación directa; sin embargo, sólo uno de los positivos por extendido fue ratificado por la PCR como verdadero positivo. La presencia de cuerpos de Howell Jolly fue el hallazgo más frecuente durante la evaluación de la morfología de los eritrocitos. Ninguno de los caprinos encontrados como positivos presentó signos compatibles con el cuadro clínico de anaplasmosis en el momento del examen, en tanto, la medición del hematocrito y la hemoglobina revelaron anemia leve en dos de los animales.

Palabras clave: anaplasmosis, diagnóstico molecular, Gen msp5, pequeños rumiantes, tinción de Giemsa.

\section{Detection of Anaplasma spp. using PCR in Goats in the Municipality of Los Santos in Santander, Colombia}

Abstract. A nested PCR assay was applied to a portion of 347 bp of the msp5 gene of Anaplasma spp. in goats of the Mesa de Los Santos, Santander. A sample of 99 animals was selected from among 600 individuals, using a proportional affixation. Each goat underwent a semiological exam and the removal of a blood sample for nested PCR assay, measurement of hematocrit, hemoglobin, evaluation of red blood cell morphology and direct observation of the microorganism in extended peripheral blood stained with Giemsa. $7.1 \%$ of the goats tested positive for PCR and $4 \%$ by direct observation; however, only one of the positives for extended peripheral blood was confirmed as a positive using PCR. Howell-Jolly bodies were the most common finding during evaluation of the morphology of erythrocytes. None of the goats found to be positive showed signs of compatibility with the clinical signs of anaplasmosis at the time of the test, while hemoglobin and hematocrit measurements indicated slight anemia in two of the animals.

Keywords: anaplasmosis, molecular diagnosis, msp5 gene, small ruminants, Giemsa staining.

\section{Deteç̧ão por PCR de Anaplasma spp. em caprinos do município de Los Santos, Santander-Colômbia}

Resumo. Mediante PCR multiplex semianidada se amplificou uma porção de $347 \mathrm{pb}$ do gene msp5 para determinar a presença de Anaplasma spp. em caprinos da Mesa de Los Santos, Santander. A partir de 600 indivíduos, selecionou-se uma amostra de 99 animais utilizando uma afixação proporcional. A cada um dos caprinos foi realizado um exame semiológico e a extração de uma amostra sanguínea para PCR semianidada, medição de hematócrito, hemoglobina, avaliação da morfologia dos glóbulos vermelhos e observação direta do micro-organismo em esfregaço sanguíneo periférico tingidos com Giemsa. 7,1\% dos caprinos resultaram positivos por PCR e 4\% por observação direta; contudo, só um dos positivos por estendido foi ratificado pela PCR como verdadeiro positivo. Os corpos de Howell Jolly foram a descoberta mais frequente durante a avaliação da morfologia dos eritrócitos. Nenhum dos caprinos encontrados como positivos apresentaram sinais compatíveis com o quadro clínico de anaplasmose no momento do exame, enquanto a medição do hematócrito e da hemoglobina revelaram anemia leve em dois dos animais.

Palavras-chave: anaplasmose, diagnóstico molecular, Gene msp5, pequenos ruminantes, coloração por Giemsa. 


\section{Introducción}

La anaplasmosis es una enfermedad infecciosa producida por Anaplasma, un parásito intracelular obligado del orden de los Rickettsiales, que infecta eritrocitos de mamíferos. La infección se encuentra distribuida en todo el mundo y es de importancia en el ganado bovino debido a las altas tasas de morbilidad y mortalidad [1].

La presencia de Anaplasma spp. en Colombia, como patógeno en los caprinos, es objeto de discusión. Sin embargo, estos pueden ser infectados por varias especies del género, entre ellas $A$. ovis, A. marginale y A. phagocytophilum [2]. Anaplasma ovis infecta caprinos y ovinos produciendo fiebre, anemia progresiva y consecuentemente reducción de la producción láctea y cárnica [2]. Anaplasma marginale afecta pequeños rumiantes causando una infección, aunque rara vez desarrollan signos clínicos [3]. Anaplasma phagocytophilum infecta a una amplia gama de hospederos como los seres humanos y los rumiantes de granja [4]. En cabras, la enfermedad cursa con síntomas subclínicos inespecíficos y puede conducir a la muerte [5]. Los caprinos pueden actuar como reservorios tanto para $A$. marginale como para A phagocytophilum [6].

En Colombia, recientemente en el departamento de Antioquia, se reportó una frecuencia del 73,7\% en caprinos y ovinos [7]. Algunos hechos pueden estar relacionados con la presencia de Anaplasma en caprinos nacionales; por ejemplo, la importación constante de ejemplares desde países en donde se ha reportado la presencia de Anaplasma spp, en pequeños rumiantes, como Venezuela y Brasil $[3,8,9]$ y la tendencia cultural de mantener a los rebaños caprinos u ovinos cerca de los vacunos [10].

Se presume que la infección podría tener impacto económico en los lugares donde la capricultura representa una fuente importante de sustento para la población rural, como es el caso de Santander, que posee la segunda mayor población caprina del país (260.000 de un total de 1.200 .000 ejemplares, estimados como población caprina de Colombia, para 2005) [9], sector que constituye el sustento casi exclusivo de por lo menos 5.000 familias en este departamento.

El objetivo de este estudio fue determinar la presencia de microorganismos del género Anaplasma en caprinos a nivel local, mediante la amplificación del gen $m s p 5$, utilizando una Reacción en Cadena de la Polimerasa (PCR) semianidada, y correlacionar la presencia del microorganismo con mediciones hematológicas y hallazgos clínico-patológicos.

\section{Materiales y métodos}

\section{Población y muestra}

Se realizó un estudio descriptivo de corte trasversal. Se seleccionaron seis fincas en el municipio de Los Santos (Santander, Colombia), con una población de 600 caprinos y un tamaño muestral de 99 , utilizando un nivel de error alfa $=0,05$ y un nivel de confiabilidad $\mathrm{z}=1,96$ [11]. El muestreo se realizó por conveniencia a individuos que presentaban síntomas como anemia, pelo hirsuto, decaimiento, retardo en el crecimiento y baja producción de leche, sin tener en cuenta la edad, sexo, raza o finalidad productiva, utilizando una afijación proporcional al tamaño poblacional de cada finca.

A cada animal se le realizó la extracción de dos muestras de sangre mediante la punción de la vena yugular. Las muestras se almacenaron en tubos con anticoagulante edta y se mantuvieron en refrigeración (4-6 $\left.{ }^{\circ} \mathrm{C}\right)$, hasta la realización de las técnicas diagnósticas.

\section{Evaluación semiológica}

Se evaluaron cada uno de los caprinos mediante un examen semiológico que incluyó sistema respiratorio, digestivo, cardiovascular, genitourinario, piel y anexos. Se prestó atención especial a la presencia de ectoparásitos y a los signos relacionados con anemia (valoración del color de las mucosas utilizando el sistema Famacha`).

\section{Mediciones hematológicas y evaluación parasitaria por observación directa}

El hematocrito (Hto) se realizó por medio de la técnica de microhematocrito [12]. La hemoglobina $(\mathrm{Hb})$ se calculó teniendo en cuenta la relación hemoglobina ( $\mathrm{g} /$ $\mathrm{dL})=$ Hematocrito (\%) / 3 [12]. Se realizó la evaluación morfológica de los glóbulos rojos, de acuerdo con lo descrito por Reagan, Sanders y DeNicofa [13]. Se realizaron extendidos finos de sangre periférica que se tiñeron con Giemsa ${ }^{\odot}$ y se observaron todos los extendidos en el microscopio en 100X en busca de hemoparásitos compatibles con la morfología del género Anaplasma (cuerpo 
redondeado denso marginado hacia la membrana del eritrocito, de color azurófilo con un halo visible y con un tamaño entre 0,3 y $1 \mu \mathrm{m}$ de diámetro).

PCR semianidada

\section{Extracción y cuantificación de ADN}

La extracción de ADN se realizó utilizando el Kit DNA $2000^{\circ}$ de CorpoGen S. A., adicionando Proteinasa K $(720 \mu \mathrm{g} / \mathrm{mL})$. Los ADN obtenidos se cuantificaron por fluorometría usando el fluorómetro Qubit Fluorometer $^{\circ}$ (Invitrogen S. A.) y posteriormente se diluyeron con buffer TE1X a una concentración de $20 \mathrm{ng} / \mu \mathrm{L}$ y se almacenaron a $-20^{\circ} \mathrm{C}$ hasta la realización de las PCR.

\section{ADN control}

A través de la vacuna comercial Anabasan Limor (1x107/2 mL de microorganismos puros vivos de Anaplasma marginale) se obtuvo el ADN genómico como control positivo; un segundo control positivo fue la mezcla de $250 \mu \mathrm{L}$ de sangre canina con $250 \mu \mathrm{L}$ de la vacuna Anabasan ${ }^{\circledR}$ Limor. Como control negativo se obtuvo ADN de $500 \mu \mathrm{L}$ de sangre humana.

\section{Condiciones de las PCR}

La PCR se realizó de acuerdo con el protocolo estandarizado por Yarce y San Juan [14] para la detección de Anaplasma spp. A cada uno de los ADN obtenidos (muestras de campo, controles positivos y control negativo) se les realizó una PCR semianidada, con una primera amplificación del gen msp5 de $714 \mathrm{pb}$, con los iniciadores externos: External Forward, 5'-GCATAGCCTCCCCCTCTTTC-3' (posición 254 a 273) y External Reverse, 5'-тсстсяссттяссCстсAga-3' (posición 710 a 692). El producto de la primera amplificación se usó como molde para la segunda reacción. En esta segunda fase se tomó $1 \mu \mathrm{L}$ del producto de la primera PCR y se amplificó una región interna de 347 pb del gen msp5 empleando el mismo iniciador reverse de la primera reacción y como iniciador Foward: 5'-TACACGTGCCCTACCGACTTA-3' (posición 367 a 387).

En cada reacción de PCR se usó una concentración final de $0,15 \mathrm{mM}$ de cada DNTP (Promega ${ }^{\circledR}$ ), $1 \mathrm{X}$ de $B u$ ffer de reacción (Kit Tucan taq polimerasa ${ }^{\circledR}$, Corpogen S.A), 2,4 $\mathrm{mM}$ de $\mathrm{Mg}_{2} \mathrm{Cl}, 0,8 \mathrm{mM}$ de cada iniciador, 0,09 $\mathrm{U} / \mu \mathrm{L}$ de Taq polimerasa (Kit Tucan taq polimerasa ${ }^{\circledR}$, Corpogen S. A.), y 100ng de ADN [14].

Para las reacciones de PCR simple se programó el termociclador (Thermo ${ }^{\circledR}$ ), con un precalentamiento a $95^{\circ} \mathrm{C}, 30$ ciclos que incluían: desnaturalización a $95^{\circ} \mathrm{C}$, asociación de iniciadores externos a $58^{\circ} \mathrm{C}$ y elongación a $72{ }^{\circ} \mathrm{C}$, finalmente una extensión a $72^{\circ} \mathrm{C}$. Para las PCR semianidadas se programaron los mismos ciclos, con excepción de la temperatura de asociación de iniciadores internos que correspondió a $62^{\circ} \mathrm{C}$ [14].

Los productos de las PCR fueron visualizados por electroforesis en gel de agarosa al 1,5\%, a 70 voltios, por una hora. Se usó un patrón de peso molecular de $100 \mathrm{pb}$ Promega ${ }^{\circledR}$. Los geles se tiñeron con Bromuro de etidio al $0,7 \%$. Al final del procedimiento, los geles se visualizaron por medio del transiluminador Uv.

\section{Análisis estadístico}

Los resultados de las PCR, de la tinción de Giemsa, de las mediciones hematológicas y de los hallazgos clínico-patológicos fueron tabulados y clasificados utilizando el programa Microsoft Office Excel 2007. Los resultados se presentaron de manera descriptiva en frecuencias y porcentajes. Para correlacionar los hallazgos clínico-patológicos y los resultados de los análisis hematológicos con la positividad por PCR se realizaron asociaciones bivariadas, utilizando la prueba de de Chi cuadrado y regresión logística o lineal simple.

\section{Consideraciones bioéticas}

De acuerdo con lo expuesto en la Resolución 008430 de 1993, se diligenció un consentimiento informado con el propietario de cada aprisco incluido en el estudio. Esta investigación fue avalada por el Comité de Bioética de la Facultad de Medicina Veterinaria y Zootecnia de la Universidad Cooperativa de Colombia, sede $\mathrm{Bu}-$ caramanga, considerando las indicaciones de la Ley 84 del 27 de diciembre de 1989, para garantizar las buenas prácticas en los procedimientos, y el bienestar de los animales incluidos en el estudio.

\section{Resultados y discusión}

Esta investigación determinó una positividad de Anaplasma spp. del 7,1\%, (7/99) en caprinos del departamento de Santander, por medio de la amplificación de una porción de $347 \mathrm{pb}$ del gen msp5 del género Anaplasma, utilizando una PCR semianidada (figura 1).

El 42,8\% (3/5) de los animales positivos por PCR tenían la hemoglobina por debajo de los rangos normales. De acuerdo con el hematocrito, el 34\% de los 


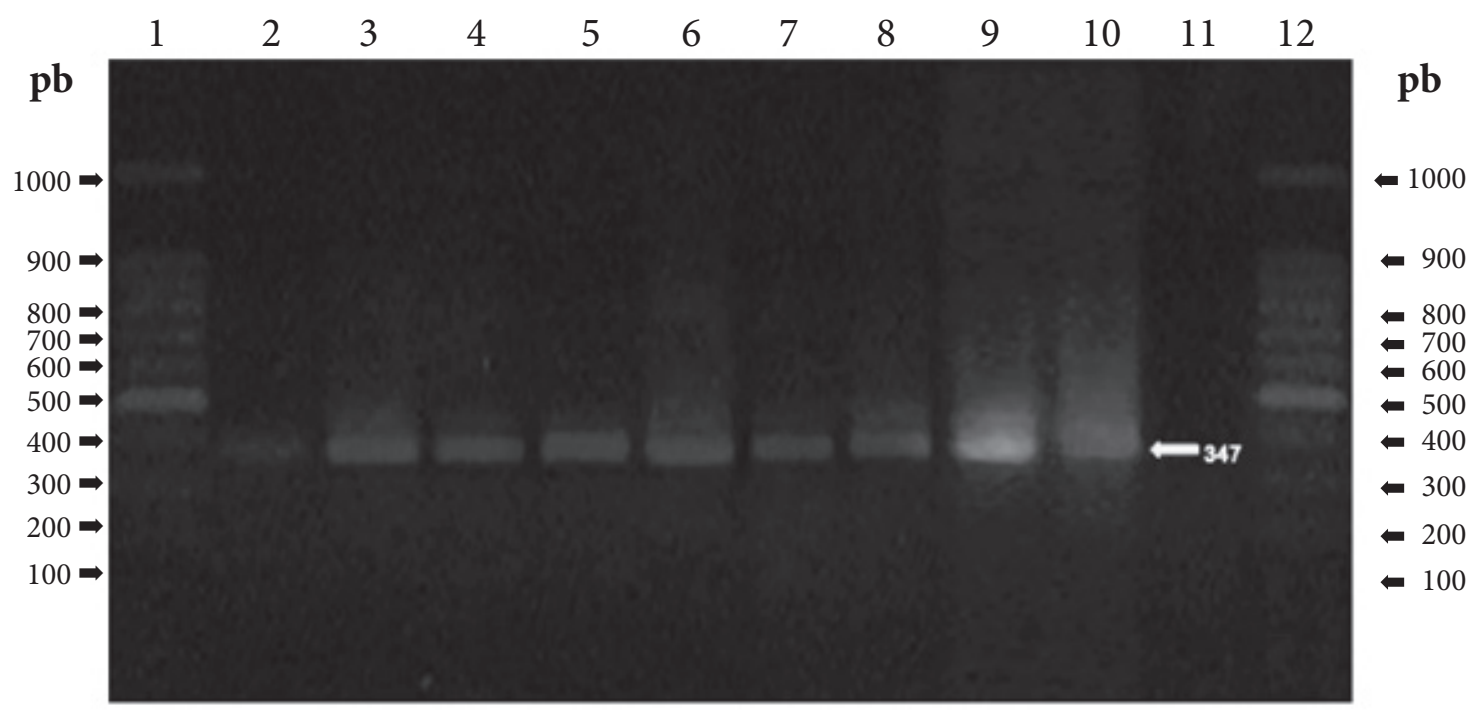

Figura 1. Electroforesis en gel de agarosa al 1,5\%. Carril 1 y 12: Patrón de peso molecular de 100 pb Promega ${ }^{\circledR}$; Carril 2 al 8: amplificados del gen msp5 a partir de siete muestras de sangre de Cabra Santandereana. Carril 9 y 10: Controles positivos Fuente: elaboración propia

animales incluidos en el estudio presentaron anemia, hecho que confirma lo descrito por N'dung, y colaboradores [10], quienes reportan porcentajes elevados de anemia en las producciones caprinas.

Conforme a lo descrito por Figueroa y colaboradores [6], la anemia leve es uno de los signos característicos de anaplasmosis crónica; sin embargo, sólo $28,5 \%$ (2/7) de los animales positivos por PCR presentaron anemia leve, lo que apoyaría la afirmación de que los individuos positivos podrían ser portadores asintomáticos y reservorios del hemoparásito.

En el momento del examen semiológico el 85,7\% (6/7) de los animales no presentó ningún signo compatible con el cuadro clínico de anaplasmosis. Este hallazgo concuerda con lo encontrado por Tavares y colaboradores en el 2010 [3], quienes no encontraron signos clínicos relacionados con anaplasmosis en los animales sero-positivos a Anaplasma spp., en su estudio. Concluyeron que el nivel de parasitemia era muy bajo y que los individuos podrían ser portadores asintomáticos y probablemente reservorios del microorganismo, y que bajo condiciones de estrés podrían alcanzar los niveles óptimos del parásito, para ser adquirido por los artrópodos vectores. En este estudio, el $71,4 \%$ (5/7) de los animales positivos por PCR presen- tó ectoparásitos al momento del examen semiológico, principalmente garrapatas y moscas.

La anormalidad morfológica de los glóbulos rojos que se halló con mayor frecuencia fue la presencia de cuerpos de Howell Jolly (82\%). También hubo una alta incidencia de anisocitosis, poiquilocitosis y punteado basófilo (con valores de 57\%, 28\% y $24 \%$, respectivamente). El 100\% (7/7) de los individuos positivos por PCR presentó cuerpos de Howell Jolly, hecho que podría ser explicado en dos de los positivos por la existencia de anemia regenerativa; sin embargo, los otros individuos no presentaban anemia, por lo que existe la posibilidad de que estos no hayan sido cuerpos de Howell Jolly sino precipitados del colorante [15]. Para los demás hallazgos de anormalidades morfológicas de los eritrocitos, como anisocitosis, poiquilocitosis, punteado basófilo y hipocromía, no existen muchas referencias en caprinos; Reagan, Sanders, y DeNicofa [13] reportan que en las especies domésticas, en general, en respuesta a las anemias regenerativas, se pueden encontrar policromatófilos, punteado basófilo y cuerpos de Howell Jolly, mientras que la hipocromía se asocia con la reducción en la cantidad de hemoglobina.

En cuanto a los resultados de los extendidos de sangre periférica se encontró que el 4,04\% (4/99) de 
los individuos presentaba corpúsculos intraeritrocitarios compatibles con Anaplasma spp.; no obstante, la PCR sólo confirmó a uno como positivo. Una posible explicación tiene que ver con la morfología poco diferencial de Anaplasma spp., que puede ser confundida fácilmente con cuerpos de Howell-Jolly o con precipitados del colorante; es muy probable que las muestras positivas por microscopía y negativas por PCR no correspondan a Anaplasma spp. sino a cuerpos de Howell Jolly [15].

La positividad de 7,1\% por PCR encontrada en este estudio es inferior a lo reportado por otros autores que usaron métodos moleculares para la detección de Anaplasma como en Kenia (22-87\%) [16], en Italia (19\%) [17], en Tailandia (16\%) [18] y en Irán (64\%) [19]. Este hecho podría estar relacionado con las diferencias climáticas determinadas por la ubicación geográfica de los países de Asia, África y Europa antes mencionados, de donde son endémicos un mayor número de géneros de garrapatas que pueden actuar como vectores biológicos [19-23].

En Estados Unidos, Ndung'u y colaboradores, en 1995 [10], reportaron una prevalencia de tan sólo el $1 \%$, explicada por la elevada tecnificación y buenas prácticas de manejo que incluían estabulación y control de ectoparásitos. En Latinoamérica, Ramos en el 2009 en Brasil [8] y Tavares y Reyna en el 2006 en Venezuela [20] encontraron prevalencias de 12 y 59\%, respectivamente. El primer estudio, más cercano a estos resultados, fue también realizado en zonas semiáridas, en donde las condiciones climáticas pueden llegar a ser adversas para los vectores de Anaplasma [8]. El segundo estudio se llevó a cabo en un área endémica a anaplasmosis bovina, donde se mantienen simultáneamente rebaños de pequeños rumiantes y de bovinos con pocas restricciones, convirtiéndose en un factor influyente.

Finalmente, aunque la presencia de Anaplasma $s p p$. en poblaciones caprinas fue reportada en Venezuela [3] y en Brasil [8] por métodos serológicos, este sería el primer informe en Latinoamérica que demuestra por métodos moleculares la presencia de Anaplasma spp. en caprinos. Previamente Tavares y Reyna en el 2006 [20] realizaron una PCR simple, para la amplificación del gen $m s p 5$, de A. marginale a muestras de sangre ovina.

\section{Referencias}

[1] Herrera M, Soto A, Urrego V, Rivera G, Zapata M, Ríos L. Frecuencia de hemoparásitos en bovinos del bajo Cauca y alto San Jorge, 2000-2005. Rev MVZ Córdoba. 2008; 13(3): 1486-94.

[2] Brenner DJ, Krieg NR, Garrity GM, Staley JT, editores. Bergey's manual of systematic bacteriology: The proteobacteria. Parte 3. Family II. Anaplasmataceae. Genus I. Anaplasma. 2 ed. Nueva York: Springer; 2005. 120-122.

[3] Tavares-Marques LM, Núñez C, Rey-Vailerón C, Reyna-Bello A. Evidencia serológica de Anaplasma spp. en pequeños rumiantes de Venezuela utilizando $m s p 5$ recombinante en ensayos inmunoenzimáticos. Rev Cient (Maracaibo). 2010; 20(5): 506-11.

[4] de la Fuente J, Lew A, Lutz H, Meli ML, Hofmann-Lehmann R, Shkap V, et al. Genetic diversity of anaplasma species major surface proteins and implications for anaplasmosis serodiagnosis and vaccine development. Anim. Health Res Rev. Jun 2005; 6(1): 75-89.

[5] Smith M, Sherman D. Goat medicine. Blood, Lymph, and Immune Systems. 2 ed. Nueva York: Editorial Wiley-Blackwell; 2009. p. 870.

[6] Figueroa M, Vargas L, Mendoza L, Acevedo O, Chavarria M, Fonseca E, Moya F. Enfermedades infecciosas de los animales domésticos en Centroamérica. San José (Costa Rica): Editorial EUNED; 1984. p. 691.

[7] Ávila-Pulgarín LS., Acevedo-Restrepo A, Jurado-Guevara JA, Polanco Echeverry D, Velázquez Vélez R, Zapata Salas R. Infección por hemoparásitos en caprinos y ovinos de apriscos de cinco municipios del norte y nororiente de Antioquia (Colombia). Ces Med Vet Zootec. $2013 ; 8(1): 11-21$.

[8] Ramos RA, Ramos CA, Araújo FR, Melo ES, Tembue AA, Faustino MA, et al. Detecção de anticorpos para anaplasma sp. em pequenos ruminantes no semi-árido do estado de Pernambuco, Brasil. Rev Bras Parasitol Vet. 2008; 17(2): 115-117.

[9] Espinal CF, Martínez H, Amézquita JE. La cadena ovinos y caprinos en Colombia. Ministerio de Agricultura y Desarrollo Rural. Observatorio Agrocadenas Colombia. Documento de Trabajo No. 125. Dic 2006.

[10] Ndung'u LW, Aguirre C, Rurangirwa FR, McElwain TF, McGuire TC, Knowles DP, Palmer GH. Detection of Anaplasma Ovis infection in goats by major surface protein 5 competitive inhibition enzyme-linked immunosorbent assay. J Clin Microbiol. Mar 1995; 33(3): 675-679. 
[11] Dohoo I, Martin S, Stryhn H. Veterinary Epidemiologic Research. Charlotetown, Prince Edward (Canadá): AVC Inc; 2003. p. 720.

[12] Arcila V, Cala F, Castellanos V. Patología y diagnóstico clínico veterinario [CD-ROOM]. Sexta edición. Bucaramanga: Universidad Cooperativa de Colombia; 2005.

[13] Reagan, WJ, Sanders, TG, DeNicofa DB. Hematología veterinaria. Atlas de especies domesticas comunes. Madrid: Harcourt Brace; 1999.

[14] Yarce F, Sanjuan J. Determinación por PCR de la posible transmisión transplacentaria de Anaplasma spp. en bovinos [Trabajo de grado]. Bucaramanga: Universidad Cooperativa de Colombia. Facultad de Medicina Veterinaria y Zootecnia; 2011. p. 158.

[15] Jiménez -Ocampo R, Rodríguez Caramillo SD, Rosario Cruz R, Orozco Vega LE, de la Fuente J. Anaplasma marginale: análisis de las secuencias del fragmento variable del gen mspla y del gen $m s p 4$ de cuatro nuevas cepas mexicanas. Téc Pecu Méx. 2008; 46(1): 69-78.

[16] Shompole S, Waghela SD, Rurangirwa FR, McGuire TC. Cloned DNA probes identify Anaplasma ovis in Goats and reveal a high Prevalence of Infection. J Clin Microbiol. Dic 1989; 27(12): 2730-5.

[17] Torina A, Vicente J, Alongi A, Scimeca S, Turla R, Nicosia $S$, et al. Observed Prevalence of tick-borne pathogens in domestic animals in Sicily, Italy during 2003-2005. Zoonoses Public Health. Journal compilation. 2007; 54(1): 8-5.
[18]. Sathaporn, J. Prevalence of anaplasmosis and eperythrozoonosis of goats in Satun province. Kasetsart J (Nat Sci). 2005; 39(5): 35-41

[19] Ahmadi-Hamedani M, Khaki Z, Rahbari S, Kazemi B, Bandehpour M. Molecular identification of anaplasmosis in goats using a new PCR-RFLP method. Iranian Journal of Veterinary Research. 2009; 10(4), Ser 29: 367-372.

[20] Tavares-Marques L, Reyna-Bello A. Estandarización de la técnica de PCR para el diagnóstico de la anaplasmosis bovina y ovina. Agronomía Trop. 2006; 56(4): 501-512.

[21] Rangel N, Rodríguez C. Determinación de seropositividad a Anaplasma phagocytophila en equinos mediante la técnica diagnóstica de inmunofluorescencia indirecta de anticuerpos (IFI) en pesebreras ubicadas en los municipios de Floridablanca, Piedecuesta, Bucaramanga y Lebrija [Trabajo de grado]. Bucaramanga: Universidad Cooperativa de Colombia; 2006. 79 p.

[22] Rymaszewska A, Grenda S. Bacteria of the genus Anaplasma characteristics of Anaplasma and their vectors: a review. Veterinarni Medicina. 2008; 53(11): 573-584.

[23] Vizcano G. Epidemiología diagnóstico y control de enfermedades parasitarias en bovinos. Anaplasmosis y babesiosis en bovinos: avances en su diagnóstico, epidemiologia y control. Compendio No. 2. Medellín: Corporación Colombiana de Investigación Agropecuaria (Corpoica); 1996. p. 93. 